\title{
Alcohol and oesophageal cancer: an assessment of the evidence from routinely collected data
}

\author{
CLAIR CHILVERS, PATRICIA FRASER, AND VALERIE BERAL \\ From the Epidemiological Monitoring Unit, London School of Hygiene and Tropical Medicine
}

SUMMARY Although various factors have been implicated in the aetiology of oesophageal cancer, one factor common to many countries is the consumption of alcoholic beverages. In England and Wales mortality from oesophageal cancer declined rapidly during the early part of this century but both mortality and incidence have increased in recent years. The generation of males born in 1906 had lower mortality than any preceding or succeeding generation. It is suggested that ages 20 to 30 may be critical in the development of oesophageal cancer and that the 1906 cohort was less exposed to alcohol than other generations. The international analysis suggests that ethyl alcohol itself rather than any specific alcoholic beverage is associated with this cancer.

Factors associated with malignant neoplasms of the oesophagus are diverse and differ according to the population studied. Alcohol, tobacco, or a combination of the two have been implicated in the United States of America (Wynder and Bross, 1961; Breslow and Enstrom, 1974), France (Audigier et al., 1975), Puerto Rico (Martinez, 1969), Singapore (de Jong et al., 1974), Norway (Bjelke, 1973), and Sweden (Wynder and Bross, 1961). Plummer-Vinson syndrome and dietary deficiencies have been associated with oesophageal cancer in Sweden (Wynder et al., 1957), Iran (Kmet and Mahboubi, 1972) and the Transkei (Rose, 1968), while the consumption of 'burning hot' beverages appears to be a significant factor in Puerto Rico (Martinez, 1969) and among the Chinese in Singapore (de Jong et al., 1974). Trauma has been suggested as a possible contributory factor among the Transkei (Rose, 1968), in Finland (Kiviranta, 1952), and in the United States of America (Bigger and Vinson, 1950). Opium in Iran (International Agency for Research on Cancer, 1976) and maize beer in Africa (Cook, 1971) have also been associated with oesophageal cancer.

A recent increase in mortality from laryngeal and oesophageal cancer in England and Wales and in Australia has been related to alcohol consumption (McMichael, 1978). In this paper, mortality and morbidity due to oesophageal cancer in England and Wales are examined in more detail and the evidence for an association with alcohol consumption is evaluated using routine data. International data on mortality and alcohol consumption are also presented.

\section{Materials and methods}

OESOPHAGEAL CANCER:

MORTALITY AND INCIDENCE

Age-specific mortality rates from oesophageal cancer in England and Wales for 1911-75 were obtained (Office of Population Censuses and Surveys, 1975a; 1977). Age-standardised cohort mortality ratios (SCMRs) (Beral, 1974) were calculated for males and females separately as summary measures of the mortality experience of each cohort.

Registrations of cancers of the oesophagus in England and Wales for 1962-63 (the first years for which all hospital regions participated in the scheme) were obtained from the Registrar General's Cancer Supplements and for 1973-74 from unpublished data supplied by six of the 15 regional cancer registries. Crude mean annual registration rates were calculated for 1962-63 and estimated for 1973-74 by calculating a rate from the regional data available.

Geographical variation in mortality was examined on a regional and international basis. Within England and Wales standardised mortality ratios (SMRs) for the standard regions subdivided into conurbations, other urban areas, and rural areas were obtained for 1969-73 from the Office of Population Censuses and Surveys. Age-specific mortality rates from oesophageal cancer in 30 countries in 1973 were obtained (World Health Organisation, 1976). Age-standardised mortality rates for ages 15 and over for each sex were calculated by the direct method using the estimated world population age structure as standard (Union Internationale Contre le Cancer, 1970). 
ALCOHOL AND TOBACCO CONSUMPTION

The quantities of wine, spirits, and beer consumed in the United Kingdom since 1900 were obtained from HM Customs and Excise and the Brewers Society. These data were converted into litres of $100 \%$ ethyl alcohol so that per caput consumption of total ethyl alcohol and of each beverage separately could be calculated.

No reliable figures were available on regional alcohol consumption in England and Wales. Mortality from cirrhosis of the liver was used as an index of alcohol consumption in the regions. This has been found to be a reasonable index (Terris, 1967) although deaths reported to be due to alcoholic cirrhosis accounted for only $15 \%$ of all male deaths from cirrhosis and $8 \%$ of female deaths in the years 1969-73 (Donnan and Haskey, 1977).

International data on alcohol consumption were obtained from Produktschap voor Gedistilleerde Dranken for 1960-61. Data on beer consumption were available for 30 countries, wine consumption for 26 countries, and spirit consumption for 18 countries. Data on total alcohol consumption expressed in terms of 50\% ethyl alcohol were available for 17 countries.

Secular and cohort trends in cigarette consumption were obtained from the Tobacco Research Council (Lee, 1976).

\section{Results}

SECULAR TRENDS

Mortality and incidence rates

Five-year age-specific death rates for successive five-year periods since 1911 for England and Wales are shown in Fig. 1. The decline in male death rates until the 1950s is striking, not least because this decline is followed by an increase in all except the oldest age groups. The female pattern is less dramatic in that the decline began later in the older age groups and was less steep, but an increase in mortality is seen in recent years.

A cohort effect is apparent for males. The cohort with mid-year of birth 1906 has the lowest death rates at ages 40-59. In general there is a progressive decline in mortality in this age group for cohorts with mid-years of birth between 1876 and 1906 and a progressive increase in mortality for cohorts born after 1906. The female cohort pattern is much less distinct and in general mortality has declined in each successive generation. Male SCMRs are at their lowest for the 1906 cohort while female SCMRs decline progressively (Table 1 ).

Oesophageal cancer registration rates in England and Wales have also increased from 54 per million in 1962-63 to 82 per million in 1973-74 for males and from 41 to 63 per million for females, increases of $52 \%$ and $54 \%$ respectively.

\section{Alcohol consumption}

Figure 2 shows per caput consumption of beer, wine $\stackrel{\varnothing}{\circ}$ spirits and total ethyl alcohol in the United Kingdom since 1900 . Wine consumption fluctuated betweerb 0.1 and 0.2 litres of pure ethyl alcohol per year untis the mid-50s, then increased fourfold between 1955 and 1974. There was a steady decline in the consumption of spirits until the end of the second world war, after which consumption increased. By
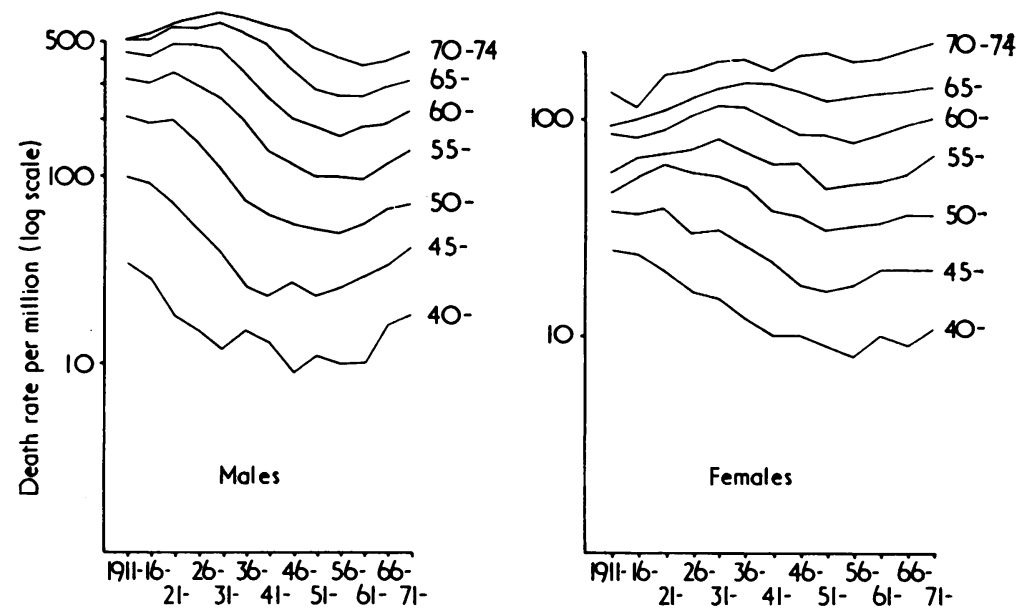

Fig. 1 Cancer of oesophagus, age-specific death rates 1911-75, England and Wales. 
Table 1 Standardised cohort mortality ratios (35-74), England and Wales, and per caput consumption of beer, wine, spirits, and 100 per cent ethyl alcohol at ages 25-29

\begin{tabular}{|c|c|c|c|c|c|c|}
\hline \multirow[b]{2}{*}{ Mid-year of birth } & \multicolumn{2}{|c|}{ Standardised cohort mortality ratios } & \multicolumn{3}{|c|}{ Per caput consumption of $100 \%$ ethyl alcohol in litres due to: } & \multirow[b]{2}{*}{ Total } \\
\hline & Males & Females & Beer & Wine & Spirits & \\
\hline $\begin{array}{l}1876 \\
1881 \\
1886 \\
1891 \\
1896 \\
1901 \\
1906 \\
1911 \\
1916 \\
1921\end{array}$ & $\begin{array}{r}127 \\
95 \\
74 \\
66 \\
63 \\
63 \\
58 \\
63 \\
70 \\
76\end{array}$ & $\begin{array}{r}124 \\
114 \\
102 \\
99 \\
95 \\
88 \\
85 \\
80 \\
78 \\
72\end{array}$ & $\begin{array}{l}4.95 \\
4.51 \\
4.86 \\
3.86 \\
3.70 \\
3.36 \\
2.69 \\
3.03 \\
3.59 \\
3.50\end{array}$ & $\begin{array}{l}0.17 \\
0.14 \\
0.14 \\
- \\
0.16 \\
0.19 \\
0.19 \\
0.23 \\
0.08 \\
0.12\end{array}$ & $\begin{array}{l}2.55 \\
2.10 \\
1.91 \\
- \\
0.93 \\
0.71 \\
0.54 \\
0.56 \\
0.51 \\
0.52\end{array}$ & $\begin{array}{l}7.67 \\
6.75 \\
6.91 \\
-4.79 \\
4.26 \\
3.42 \\
3.82 \\
4.18 \\
4.14\end{array}$ \\
\hline & & $\begin{array}{l}\text { Males } \\
\text { Females }\end{array}$ & $\begin{array}{l}0.76 \\
0.81\end{array}$ & $\begin{array}{r}-0.13 \\
0.06\end{array}$ & $\begin{array}{l}0.84 \\
0.96\end{array}$ & $\begin{array}{l}0.82 \\
0.91\end{array}$ \\
\hline
\end{tabular}

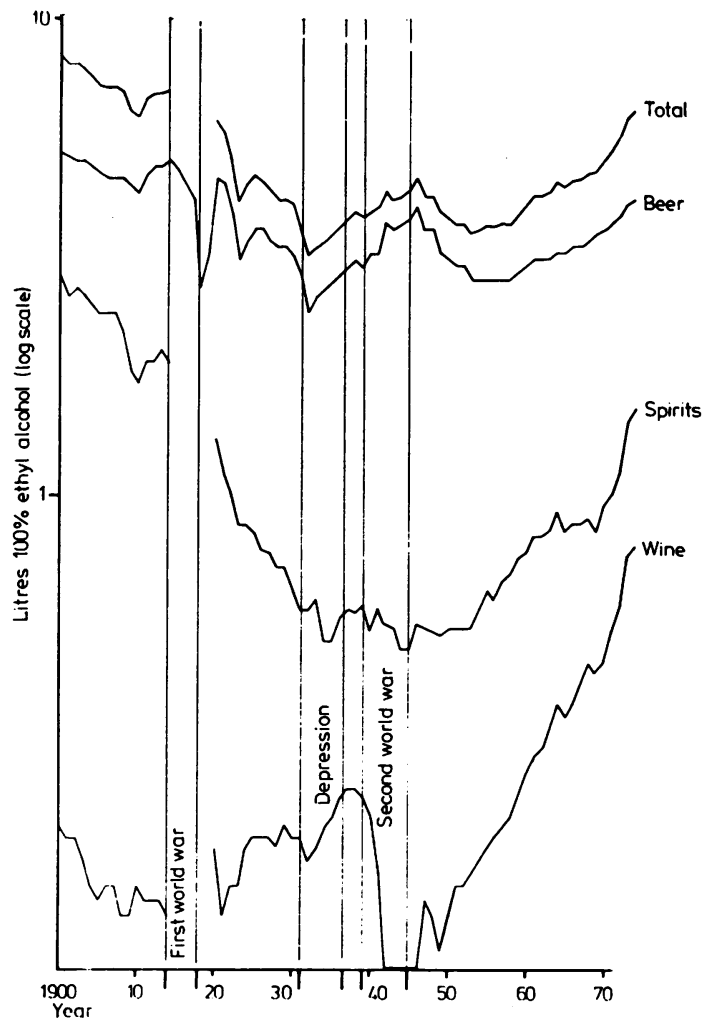

Fig. 2 Per caput consumption of alcoholic beverages, United Kingdom, 1900-1974.

1974 the level of consumption in 1900 had not been regained. Consumption of beer has contributed most to total alcohol ingestion throughout this century. Consumption levels fell from $5 \cdot 2$ litres of pure ethyl alcohol in 1900 to a minimum of 2.4 litres of absolute alcohol per caput during the depression, with another decline in the 1950 s. Since then consumption has increased steadily. Consumption of spirits fell from 2.9 litres of absolute alcohol per caput in 1900 to 0.5 litres between 1935 and 1950 , but by 1974 it had risen to 1.5 litres per caput. The pattern of total alcohol consumption is similar to that of beer, its major component. The proportion of total consumption attributable to beer increased from $63 \%$ in 1900 to $80 \%$ in 1930 , but by 1974 it had returned to the 1900 level. Spirits show a reverse pattern. Wine consumption in 1900 accounted for $2 \%$ of total alcohol consumption but by 1974 its share had risen to $12 \%$.

In Table 1 the SCMRs for male and female cohorts with mid-years of birth 1876-1921 are related to average per caput consumption of beer, wine, spirits, and total ethyl alcohol at the time when each cohort was aged 25-29. For both males and females, cohort mortality is closely correlated with the per caput consumption of total alcohol when the cohort was aged 25-29 (correlation coefficients: for males $r=0.84, \quad P<0.01$; females $r=0.88, P<0.01)$. When the individual beverages are analysed separately, both beer and spirit consumption are closely related to cohort mortality.

\section{Cigarette consumption}

In the United Kingdom cigarette smoking has increased steadily since 1905 except for a sharp decline between 1946 and 1950 . Consumption by successive male and female cohorts increased with year of birth until the cohort with mid-year of birth 1921 , after which consumption declined for males. Succeeding female cohorts have continued to increase their lifetime cigarette consumption. There was no relationship between cigarette consumption in different generations and oesophageal cancer mortality. 


\section{GEOGRA PHICAL CORRELATION}

\section{Regional}

The nine standard regions of England and Wales before reorganisation in 1974 can be subdivided into conurbations, urban areas excluding the conurbations, and rural areas. There are 26 such subdivisions, and mortality data are available for all of them. Fig. 3 shows male SMRs for 1969-73 for cirrhosis of the liver plotted against SMRs for malignant neoplasm of the oesophagus for each of these $\mathbf{2 6}$ areas. Mortality from these causes is highly correlated on a regional basis $(r=0 \cdot 66, P<0 \cdot 1)$. For females no such correlation is found $(r=0.11$, $\mathbf{P}>\mathbf{0} \cdot \mathbf{1})$.

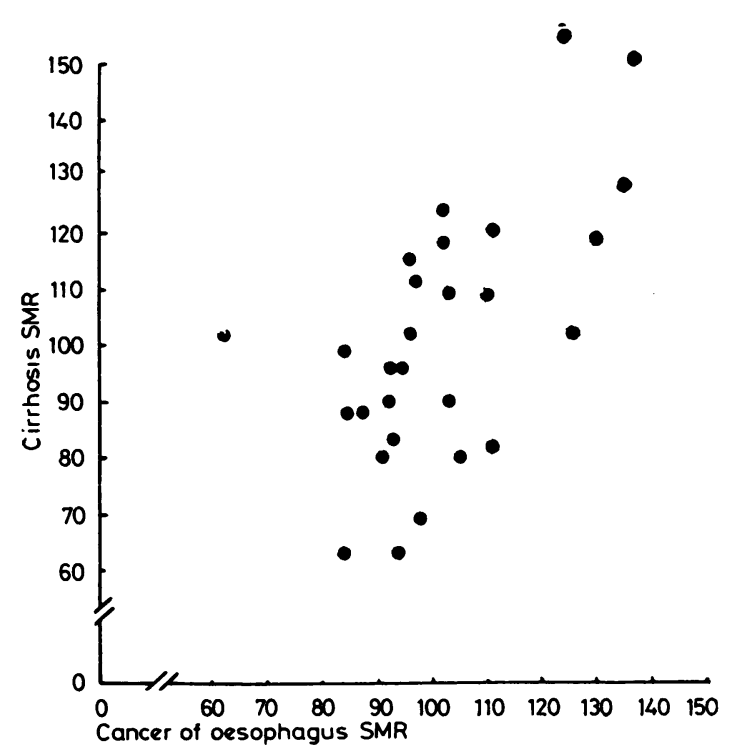

Fig. 3 Cancer of oesophagus and cirrhosis of liver. Mortality by subdivisions of standard regions, England and Wales (males), 1969-1973.

\section{International}

Table 2 shows per caput consumption of beer, wine, spirits, and 50\% ethyl alcohol, and the male and female age-standardised death rates from oesophageal cancer in 30 countries. Consumption in 1960-61 was related to mortality in 1973 in order to allow for latency between exposure and development of the cancer. Correlation coefficients were calculated between mortality rates and per caput consumption of each alcoholic beverage separately, and for total alcohol. For females there is no association between alcohol consumption and oesophageal cancer on an international basis. For males, however, an association is evident between total alcohol consumption and oesophageal cancer $(r=0.80, P<0 \cdot 01)$. There is a weaker association with wine consumption $(r=0.47, P<0.05)$, but no association with either beer or spirit consumption.

\section{Discussion}

Since 1911 mortality from oesophageal cancer has declined dramatically in England and Wales in all except the oldest age groups (Fig. 1). However, in recent years there has been a disturbing increase not only in mortality but in the incidence of this condition. It is possible that the increase in incidence as measured by the voluntary cancer registration system is an artefact caused by more complete registration of cases. If this were so, the increase in mortality would have to be explained by an increase in case fatality. Such an explanation is unlikely, since the corrected five-year survival rates for cases registered between 1962 and 1966 (written communication) increased for both males and females (Office of Population Censuses and Surveys, 1975b). In parallel with the changing mortality pattern but preceding it by some $20-25$ years, there has been a change in the pattern of consumption of alcoholic beverages (Fig. 2).

Among males in Great Britain mortality was $\overrightarrow{\mathbb{D}} \vec{\sim}$ lowest in the cohort with mid-year of birth 1906 ? (Table 1). This cohort was aged 25-29 during the early 1930s when alcohol consumption was at its lowest ever. In a study of English alcoholics it was found that male alcoholics on average first became drunk at the age of 20 and first suffered from amnesiaco at the age of 30 (Glatt, 1961). It is therefore likely? that the habit of drinking heavily becomes established at ages 20 to 30 , and that the 1906 cohort was less exposed to alcohol in the form of both beer and spirits at this critical age and therefore less likely to drink habitually than preceding or succeeding generations. This may now be reflected in the subsequent low mortality of this cohort from oesophageal cancer, and in the high correlation between the mortality of cohorts born between 1876 and 1921 and their average per caput consumption of beer, spirits and total ethyl alcohol at ages 25 to 29 . Two possible mechanisms linking alcohol consumption at ages 20 to 30 with subsequent mortality from oesophageal cancer are consistent with the data presented here. An individual's lifetime pattern of alcohol consumption may be determined by consumption at an early age, malignant change may be initiated at this age, or both mechanisms may operate. On the basis of routine statistics we are unable to distinguish between these explanations, but alcohol consumption at ages 20 to 30 appears to be a factor in the subsequent development of oesophageal cancer.

In view of the association between alcohol 
Table 2 Per caput consumption of beer, wine, spirits, and 50\% ethyl alcohol, 1960-62, and standardised death rates from oesophageal cancer, 1973

\begin{tabular}{|c|c|c|c|c|c|c|}
\hline \multirow[b]{2}{*}{ Country } & \multicolumn{2}{|c|}{ Standardised death rate per million } & \multicolumn{4}{|c|}{ Alcohol consumption } \\
\hline & Male & Female & $\begin{array}{l}\text { Beer } \\
\text { (litres) }\end{array}$ & $\begin{array}{l}\text { Wine } \\
\text { (litres) }\end{array}$ & $\begin{array}{l}\text { Spirits } \\
\text { (litres at 100\%) }\end{array}$ & $\begin{array}{l}\text { Litres } \\
\text { s0\% ethyl alcohol }\end{array}$ \\
\hline Uruguay & 203.94 & 48.41 & $22 \cdot 0$ & $21 \cdot 0$ & - & - \\
\hline France & 203.09 & $17 \cdot 28$ & $35 \cdot 4$ & 126.9 & $2 \cdot 0$ & $35 \cdot 8$ \\
\hline Chile & $155 \cdot 55$ & $68 \cdot 58$ & $30 \cdot 0$ & $46 \cdot 0$ & - & - \\
\hline Switzerland & $116 \cdot 75$ & 15.96 & $62 \cdot 5$ & $36 \cdot 0$ & $1 \cdot 58^{*}$ & $17 \cdot 4$ \\
\hline Japan & $111 \cdot 81$ & $26 \cdot 68$ & 9.9 & 0.1 & - & - \\
\hline Portugal & 93.72 & $32 \cdot 70$ & $3 \cdot 0$ & $85 \cdot 0$ & - & - \\
\hline Luxemburg & 86.42 & 19.46 & $116 \cdot 4$ & $31 \cdot 3$ & 1.0 & $17 \cdot 6$ \\
\hline England and Wales & $74 \cdot 74$ & $39 \cdot 75$ & $85 \cdot 2$ (UK) & 1.6 (UK) & 0.8 (UK) & $10 \cdot 8$ (UK) \\
\hline Italy & $70 \cdot 59$ & $11 \cdot 80$ & $5 \cdot 1$ & $108 \cdot 3$ & 1.0 & $26 \cdot 3$ \\
\hline Spain & $69 \cdot 28$ & $14 \cdot 14$ & $11 \cdot 0$ & 50.7 & - & - \\
\hline Poland & $66 \cdot 70$ & $13 \cdot 74$ & $22 \cdot 8$ & $4 \cdot 5$ & 2.4 & $8 \cdot 2$ \\
\hline Paraguay & $65 \cdot 03$ & $17 \cdot 48$ & 2.9 & - & - & - \\
\hline Venezuela & $62 \cdot 86$ & $37 \cdot 07$ & $36 \cdot 0$ & - & - & - \\
\hline Finland & 58.81 & 39.86 & $25 \cdot 0$ & $1 \cdot 3$ & $1 \cdot 3$ & $4 \cdot 8$ \\
\hline United States of America & $58 \cdot 54$ & $16 \cdot 57$ & $58 \cdot 5$ & 3.4 & $2 \cdot 1$ & $10 \cdot 8$ \\
\hline Australia & $58 \cdot 35$ & 22.96 & $102 \cdot 7$ & $5 \cdot 1$ & 0.8 & $13 \cdot 0$ \\
\hline Austria & $54 \cdot 88$ & $10 \cdot 70$ & $71 \cdot 9$ & $20 \cdot 7$ & 2.4 & $13 \cdot 7$ \\
\hline Canada & $51 \cdot 67$ & 15.90 & $60 \cdot 0$ & $2 \cdot 0$ & $1 \cdot 7$ & $10 \cdot 3$ \\
\hline Germany & $51 \cdot 17$ & $10 \cdot 74$ & $94 \cdot 7$ & $10 \cdot 8$ & 1.9 & $17 \cdot 1$ \\
\hline Iceland & $48 \cdot 54$ & 6.75 & $7 \cdot 8$ & - & 1.6 & - \\
\hline Denmark & 44.78 & 15.00 & 71.9 & $3 \cdot 1$ & 0.6 & $7 \cdot 7$ \\
\hline Holland & $41 \cdot 58$ & $14 \cdot 83$ & 23.9 & 1.9 & $1 \cdot 1$ & 5.6 \\
\hline Norway & 39.93 & 11.57 & $24 \cdot 5$ & $1 \cdot 2$ & $1 \cdot 3$ & 5.4 \\
\hline Sweden & $39 \cdot 72$ & 15.00 & $37 \cdot 0$ & $3 \cdot 3$ & $2 \cdot 3$ & $8 \cdot 0$ \\
\hline Yugoslavia & $39 \cdot 71$ & $9 \cdot 30$ & 6.7 & $21 \cdot 4$ & - & - \\
\hline Hungary & 33.68 & $7 \cdot 14$ & $36 \cdot 7$ & 29.9 & 1.4 & $13 \cdot 3$ \\
\hline Romania & $28 \cdot 12$ & 5.45 & 8.8 & 21.7 & - & - \\
\hline Greece & $25 \cdot 94$ & $11 \cdot 23$ & $5 \cdot 5$ & $40 \cdot 8$ & - & - \\
\hline Mexico & $21 \cdot 12$ & $9 \cdot 51$ & 22.9 & - & - & - \\
\hline Bulgaria & $18 \cdot 55$ & 5.29 & 13.0 & $20 \cdot 2$ & - & - \\
\hline
\end{tabular}

\begin{tabular}{|c|c|c|c|}
\hline \multirow[b]{2}{*}{ Alcoholic beverage } & \multicolumn{2}{|c|}{ Correlation coefficient } & \multirow[b]{2}{*}{ No. of countries } \\
\hline & Males & Females & \\
\hline $\begin{array}{l}\text { Beer } \\
\text { Wine } \\
\text { Spirits }\end{array}$ & $\begin{array}{l}0.03 \\
0.47 \\
0.14\end{array}$ & $\begin{array}{r}0.06 \\
0.03 \\
-0.36\end{array}$ & $\begin{array}{l}30 \\
26 \\
18\end{array}$ \\
\hline Ethyl alcohol & 0.80 & -0.20 & 17 \\
\hline
\end{tabular}

- Data for 1961.

Source: Produktschap voor Gedistilleerde Dranken.

consumption, smoking, and oesophageal cancer (Wynder and Bross, 1961) time trends in per caput cigarette consumption were also examined. There was no decrease in cigarette consumption to account for the decline in oesophageal cancer during the first half of this century. Moreover, cohort trends in male cigarette smoking are unrelated to cohort mortality from oesophageal cancer. It therefore seems unlikely that cigarette smoking is an important factor in the aetiology of oesophageal cancer in England and Wales.

The geographic analysis within England and Wales confirms the association with alcohol consumption in males although the evidence is indirect (Fig. 3). The low correlation between mortality from cirrhosis of the liver and oesophageal cancer in females may be due to the fact that in women alcoholic cirrhosis is reported for only $\mathbf{8 \%}$ of all cirrhotic deaths, although this is likely to be a considerable underestimate. A similar analysis of mortality from oesophageal cancer and cirrhosis of the liver on an occupational basis was also carried out. Of the 15 occupational groups with the highest SMRs from cirrhosis of the liver, all but three also had greater than expected mortality from oesophageal cancer. However, the numbers of deaths in all but a few groups were too small to enable any firm inference to be made.

Additional evidence for the association is found in the fact that male mortality rates exceed female rates. It is well known that in the past male consumption of alcohol has been greater than female consumption. However the recent upturn in female mortality could possibly be due to an increase in alcohol consumption by females during recent years.

Although an association between alcohol consumption and oesophageal cancer has been 
observed in some countries, this is by no means universal. The international correlations observed here indicate a strong association between total alcohol consumption and oesophageal cancer mortality, and a smaller association between wine consumption and mortality. This is true only for males. These results should be interpreted with caution. Differences in death registration procedures in different countries may introduce bias, as may variability in the accuracy of the alcohol consumption data. The absence of significant correlation between female mortality and alcohol consumption could also be explained by the different patterns of female drinking. Attitudes to female drinkers differ between countries (Moser, 1974); as a result, the proportion of female drinkers and their share of total consumption differs between countries, so that any association is likely to be masked. The fact that mortality is highly correlated with total alcohol consumption rather than with a specific type of beverage on an international basis suggests that carcinogenesis may be related to ethyl alcohol alone, or in combination with some other unidentified substance, rather than to any contaminant of specific alcoholic beverages.

This finding contrasts with that of Tuyns (1970) in his comparison of mortality from oesophageal cancer, cirrhosis, and alcoholism among males in the départements of France. He found a closer association between mortality from alcoholism and oesophageal cancer than between cirrhosis and oesophageal cancer. On the assumption that, in general, spirit drinking is related to alcoholism whereas wine and beer drinking is related to cirrhosis, he concluded that spirits rather than wine and beer are more closely related to the development of oesophageal cancer. This view is not universally held. Wine and beer were once believed to be most harmful, but it is now recognised that spirits are equally liable to lead to cirrhosis (Sherlock, 1975).

In England and Wales throughout this century, the patterns of beer and spirit consumption have been similar. Until 1972 wine represented less than $10 \%$ of total ethyl alcohol consumption. Therefore total alcohol, beer, and spirit consumption are all closely correlated with mortality. With the increasing consumption of wine and spirits relative to beer since the mid-1940s, observation of the mortality from oesophageal cancer of cohorts born since the 1920 s will be of particular interest.

Although many factors have been implicated in the aetiology of oesophageal cancer (Wynder and Mabuchi, 1973), one common factor in the United States of America, Australia, Western Europe, and Scandinavia is the consumption of alcoholic beverages. In Great Britain there is considerable cause for concern as alcohol consumption, and, in particular, the consumption of wine and spirits, continues to increase (British Medical Journal, 1978). Trends in mortality and alcohol consumption over time and on a geographical basis support the hypothesis that for males at least, alcohol is an important factor in the aetiology of oesophageal cancer.

This work was supported by the Medical Research Council. We thank Dr. A. M. Adelstein of the Office of Population Censuses and Surveys for allowing us to use unpublished data; H.M. Customs and Excise, the Brewers Society and the Government Chemist for help with estimating alcohol consumption; and Ms Josephine Thiedeman for computing assistance.

Reprints from Clair Chilvers, present address: Division of Epidemiology, Institute of Cancer Research, Clifton Avenue, Sutton, Surrey SM2 5PX.

References

Audigier, J. C., Tuyns, A. J., and Lambert, R. (1975). Epidemiology of oesophageal cancer in France. Digestion, 13, $209-219$.

Beral, V. (1974). Cancer of the cervix: a sexually transmitted infection? Lancet, 1, 1037-1040.

Bigger, I. A., and Vinson, P.P. (1950). Carcinoma secondary to burn of the esophagus from ingestion of lye. Surgery, 28, 887-889.

Bjelke, E. (1973). Alcohol use and rates of cirrhosis of the liver and cancer of the digestive tract: secular changes and areal variation in Norway. Paper read to the International Agency for Research on Cancer, Lyon.

Breslow, N. E., and Enstrom, J. E. (1974). Geographic correlations between cancer mortality rates and alcohol-tobacco consumption in the United Stares. Journal of the National Cancer Institute, 53, 631-639.

British Medical Journal (1978). Three centuries of British drinking. British Medical Journal, 1, 1373.

Cook, P. (1971). Carcinoma of the oesophagus in Africa. British Journal of Cancer, 25, 853-880.

de Jong, U. W., Breslow, N., Goh Ewe Hong, J., Sridharan, M., and Shanmugaratnam, K. (1974). Aetiological factors in oesophageal cancer in Singapore Chinese. International Journal of Cancer, 13, 291-303.

Donnan, S., and Haskey, J. (1977). Alcoholism and cirrhosis of the liver. Population Trends, 7, 18-24.

Glatt, M. M. (1961). Drinking habits of English (middle class) alcoholics. Acta Psychiatrica Scandinavica, 37, 88-113.

International Agency for Research on Cancer. (1976). Annual Report. WHO: Lyon.

Kiviranta, U. K. (1952). Corrosion carcinoma of the esophagus. Acta Oto-Laryngologica (Stockholm), 42, 89-95.

Kmet, J., and Mahboubi, E. (1972). Esophageal cancer in the Caspian Littoral of Iran: Initial studies. Science, 175, 846-853.

Lee, P. N. (1976). Statistics of smoking in the United Kingdom. Tobacco Research Council Research Paper No. 1, 7th Edition. Tobacco Research Council: London.

Martinez, I. (1969). Factors associated with cancer of the oesophagus, mouth, and pharynx in Puerto Rico. Journal of the National Cancer Institute, 42, 1069-1094.

McMichael, A. J. (1978). Increase in laryngeal cancer in Britain and Australia in relation to alcohol and tobacco consumption trends. Lancet, 1, 1244-1247. 
Moser, J. (1974). Problems and programmes related to alcohol and drug dependence in 33 countries. World Health Organisation: Geneva.

Office of Population Censuses and Surveys (1975a). Cancer Mortality England and Wales 1911-1970. Studies on Medical and Population Subjects No. 29. HMSO: London.

Office of Population Censuses and Surveys (1975b). Registrar General's Supplement on Cancer 1968-1970. HMSO: London.

Office of Population Censuses and Surveys (1977). Mortality Surveillance 1968-75. HMSO: London.

Rose, E. F. (1968). Carcinogenesis and oesophageal insults. South African Medical Journal, 42, 334-336.

Sherlock, S. (1975). Diseases of the Liver and Biliary System, 5th edition, p. 449. Blackwell: Oxford.

Terris, M. (1967). Epidemiology of cirrhosis of the liver: national mortality data. American Journal of Public Health, 57, 2076-2088.
Tuyns, A. J. (1970). Cancer of the oesophagus: further evidence of the relation to drinking habits in France. International Journal of Cancer, 5, 152-156.

Union Internationale Contre le Cancer (1970). Cancer Incidence in Five Continents, Volume II. Springer-Verlag: Berlin-Heidelberg-New York.

World Health Organisation (1976). World Health Statistics Annual Volume 1. WHO: Geneva.

Wynder, E. L., and Bross I. J. (1961). A study of etiological factors in cancer of the esophagus. Cancer, 14, 389-413.

Wynder, E. L., Hultberg, S., Jacobsson, F., and Bross, I. J. (1957) Environmental factors in cancer of the upper alimentary tract. Cancer, 10, 470-487.

Wynder, E. L., and Mabuchi, K. (1973). Etiological and environmental factors in esophageal cancer. Journal of the American Medical Association, 226, 1546-1548. 